Article

\title{
A Sensitive DNAzyme-Based Chiral Sensor for Lead Detection
}

\section{Hua Kuang *, Honghong Yin, Changrui Xing and Chuanlai Xu}

State Key Lab of Food Science and Technology, School of Food Science and Technology, Jiangnan University, Wuxi, Jiangsu 214122, China; E-Mails: yin0713@126.com (H.Y.); da_rui12345@163.com (C.X.); xcl@jiangnan.edu.cn (C.X.)

* Author to whom correspondence should be addressed; E-Mail: kuangh@jiangnan.edu.cn; Tel./Fax: +86-5108-5329-076.

Received: 7 October 2013; in revised form: 25 October 2013 / Accepted: 25 October 2013 / Published: 1 November 2013

\begin{abstract}
A DNAzyme-based sensor for the determination and quantification of lead ions $\left(\mathrm{Pb}^{2+}\right)$ has been established, which combines the recognition and catalysis of DNAzyme with the optical properties of nanomaterials. Circular dichroism (CD) signals were obtained by a DNAzyme-based assembly of asymmetric silver nanoparticle (AgNPs) dimers. A good linear relationship between $\mathrm{CD}$ signals and $\mathrm{Pb}^{2+}$ concentration was obtained ranging from $0.05 \mathrm{ng} \cdot \mathrm{mL}^{-1}$ to $10 \mathrm{ng} \cdot \mathrm{mL}^{-1}$ with a limit of detection (LOD) of $0.02 \mathrm{ng} \cdot \mathrm{mL}^{-1}$. The specificity of this sensor in lead ion detection was excellent, and a satisfactory recovery was obtained in the analysis of tap water samples. The proposed technique possesses both high sensitivity and good specificity, giving it great potential for the analysis of $\mathrm{Pb}^{2+}$ in water.
\end{abstract}

Keywords: lead; detection; DNAzyme; circular dichroism (CD); sensor

\section{Introduction}

Of the various heavy metal ions found in the environment, lead is a major environmental pollutant and can produce toxic effects in plants and animals due to its non-degradation and persistence in the environment. Human exposure to lead results in renal dysfunction, as well as various neurotoxic symptoms [1-4]. Traditional methods for lead detection include inductively coupled plasma mass spectrometry (ICP-MS) and atomic absorption/emission spectrometry [5,6]. However, high cost, sophisticated instrumentation and complicated sample pretreatment restrict the wide application of these techniques. 
DNAzymes, which belong to functional DNA molecules isolated via in vitro selection, have been shown to serve as biocatalysts for their recognition of a large variety of targets in chemical transformations [7]. RNA-cleaving DNAzymes have the merits of simple reaction conditions and fast turnover rates, and have been widely used in the detection of analytes [8-10]. DNAzymes, different from protein enzymes, can be synthesized by simple chemical reaction and have been verified as having good thermal stability and activity. As oligonucleotides, DNAzymes can be easily modified using various functional groups and immobilized on solid supports. The integration of DNAzymes with nano-materials has opened an important field in sensor technology, and gives a great advantage for specific molecular recognition and signal transduction based on nano-particles (NPs) [11]. This strategy was first employed by Liu and $\mathrm{Lu}$, who used a metal ions specific DNAzyme for the construction of various types of sensors for selective and sensitive detection [12-16]. Their work included the use of a $\mathrm{Pb}^{2+}$-specific DNAzyme known as "8-17" for $\mathrm{Pb}^{2+}$ detection $[17,18]$. Following, the formation of numerous DNAzyme-NPs, sensors were developed using various converted signals such as colorimetric signals, dynamic light scattering (DLS), fluorescence, electrochemical signals, chemiluminescent signals, and surface enhanced Raman scattering (SERS) [17,19-24].

Circular dichroism (CD) spectra originating from chiral nanostructures assembled by plasmonic NPs have received more interest recently [25-27]. The CD signal of assembled NPs was first reported by Alivisato's group [28]. There, the CD signal of NPs and nanorods arranged in nanometre-scale helices driven by DNA hybridization were reported [29-33]. Gold nanoparticle dimers and gold nanorod ladder assemblies through immuno-recognition were designed to detect antigens by our group [34,35].

In this work, a $\mathrm{Pb}^{2+}$-specific DNAzyme was used in the formation of asymmetric silver nanoparticles (AgNPs). In the absence of $\mathrm{Pb}^{2+}$, DNA-modified AgNPs dimers were formed. In contrast, the presence of $\mathrm{Pb}^{2+}$ induced the DNAzyme to cleave the substrate strand into two pieces, and the dimers were disassembled. The resulting CD signal from assembled AgNPs was found to have a linear relationship with the $\mathrm{Pb}^{2+}$ level.

\section{Results and Discussion}

The sensing principle for $\mathrm{Pb}^{2+}$ detection is illustrated in Figure 1. The DNAzyme-based sensor consisted of four DNA sequences. The DNAzyme known as "8-17" was composed of an enzyme strand (17E) and a substrate strand (Sub). S1 and S2 were coupled with $20 \mathrm{~nm}$ and $10 \mathrm{~nm} \mathrm{AgNPs,}$ respectively. The substrate strand was extended at both ends by 12 bases, which were complementary to the DNA fragments $(\mathrm{S} 1, \mathrm{~S} 2)$ attached to AgNPs. AgNP dimers were assembled by hybridization of the four DNA fragments, and the CD signal was produced by the asymmetric structure. In the presence of $\mathrm{Pb}^{2+}$, the substrate strand was cleaved at the single RNA cleavage site, therefore, the AgNP dimers were disassembled into single NPs by processing at $50{ }^{\circ} \mathrm{C}$. 
Figure 1. The principle of a DNAzyme-based chirality sensor for $\mathrm{Pb}^{2+}$ detection.

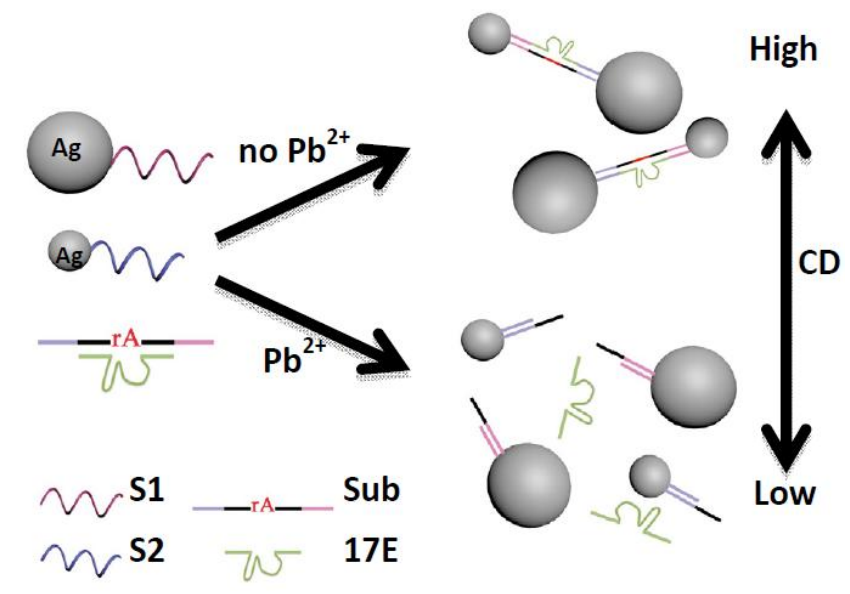

The TEM images of the two scales of AgNPs showed that they were mono-dispersed (Figure 2a,b ), and the UV spectrum of $20 \mathrm{~nm}$ AgNPs was larger than that of $10 \mathrm{~nm} \mathrm{AgNPs}$ (Figure S1). Without $\mathrm{Pb}^{2+}$ ions, the asymmetric AgNP dimers were successfully assembled and the hydrodynamic sizes of the assembled dimers were obviously bigger when compared with single NPs (Figure S2). The yield of the dimer assembly was high using the optimized coupling ratio of DNA and AgNPs (10:1). The concentration of Sub and 17E had little influence on dimer assembly. An adequate amount of Sub and $17 \mathrm{E}$ were provided for hybridizing with S1 and S2. Using centrifugation, the unreacted DNA was successfully removed (Figure 2c).

Figure 2. Representative TEM images of AgNPs: (a) dispersed single $20 \mathrm{~nm}$ AgNPs; (b) dispersed single $10 \mathrm{~nm}$ AgNPs; and (c) a symmetric AgNP dimers.

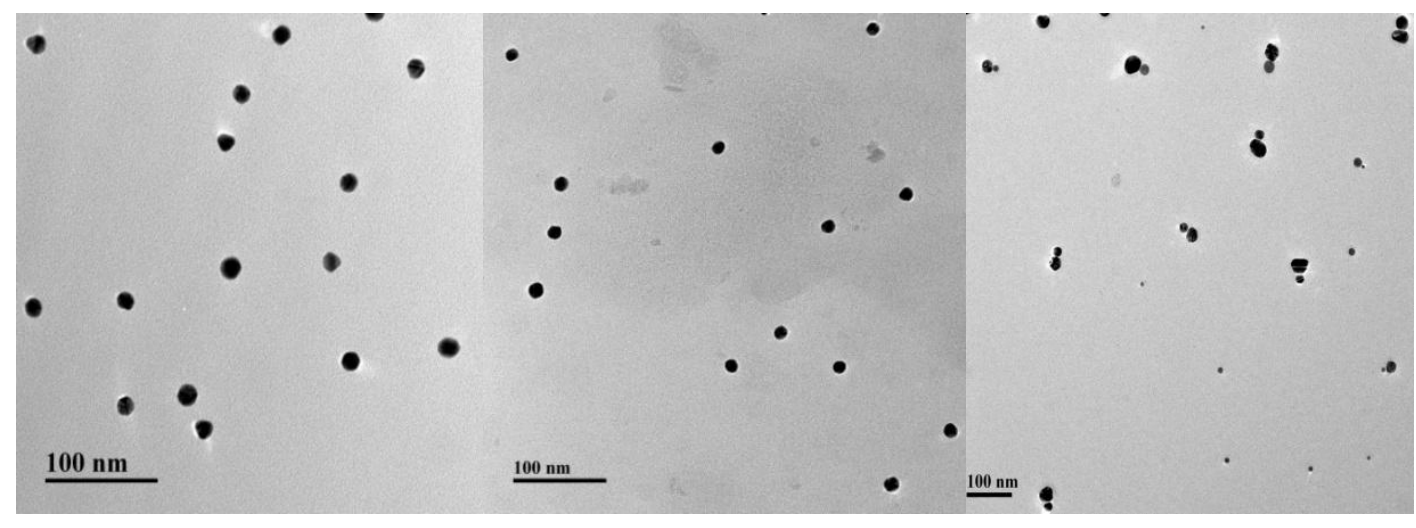

(a)

(b)

(c)

The sensitivity of the sensor was influenced by the intensity of the CD signals, which were closely related to the number of AgNP dimers. The more AgNP dimers present, the higher the CD signal intensity. Under optimized conditions, the sensitivity of this method was evaluated using different concentrations of $\mathrm{Pb}^{2+}$ standard samples $\left(0.05,0.1,0.5,1,2,5\right.$, and $\left.10 \mathrm{ng} \cdot \mathrm{mL}^{-1}\right)$. The $\mathrm{CD}$ intensities are shown in Figure 3a. With an increase in $\mathrm{Pb}^{2+}$ concentration, the $\mathrm{CD}$ intensity decreased. However, the UV signal showed almost no obvious change, as for the hydrodynamic diameters under different assembly states (Figure S3, Figure S4). The standard curve of $\mathrm{Pb}^{2+}$ detection was constructed using the $\mathrm{CD}$ intensity and the concentrations of $\mathrm{Pb}^{2+}$. A good linear relationship with a correlation coefficient of 
0.9905 was observed in the test range from $0.05 \mathrm{ng} \cdot \mathrm{mL}^{-1}$ to $10 \mathrm{ng} \cdot \mathrm{mL}^{-1}$ and the LOD was $0.02 \mathrm{ng} \cdot \mathrm{mL}^{-1}$ (Figure 3b). Kim et al. [36] summarized the fluorescent and colorimetric sensors for lead detection in 2012 and the reported sensors have a sensitivity ranging from $\mathrm{ng} \cdot \mathrm{mL}^{-1}$ level to $\mathrm{mg} \cdot \mathrm{mL}^{-1}$ level. In comparison with the immune-strip measure (LOD value of $2 \mathrm{ng} \cdot \mathrm{mL}^{-1}$ ), the sensor based on the CD signal is much more sensitive for lead detection [37]. With a unique CD signal, the proposed sensor here manifests excellent sensitivity.

Figure 3. (a) CD spectrum under different concentrations of $\mathrm{Pb}^{2+}(0,0.05,0.1,1,2,5$, and $\left.10 \mathrm{ng} \cdot \mathrm{mL}^{-1}\right)$; and (b) linear relationship for the determination of $\mathrm{Pb}^{2+}$.

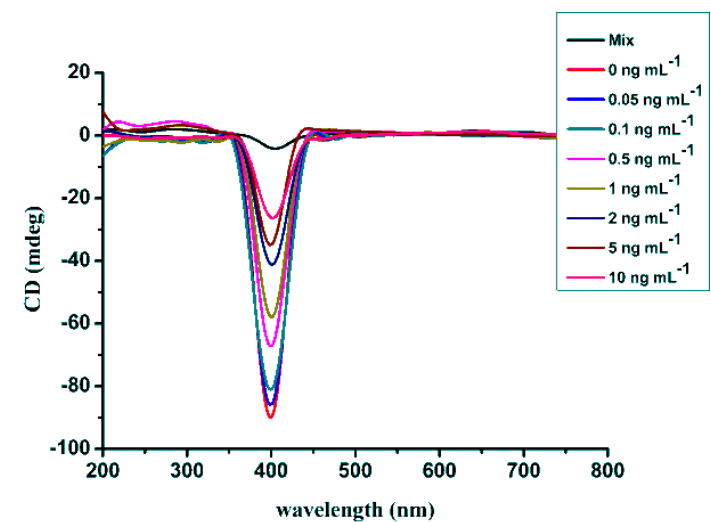

(a)

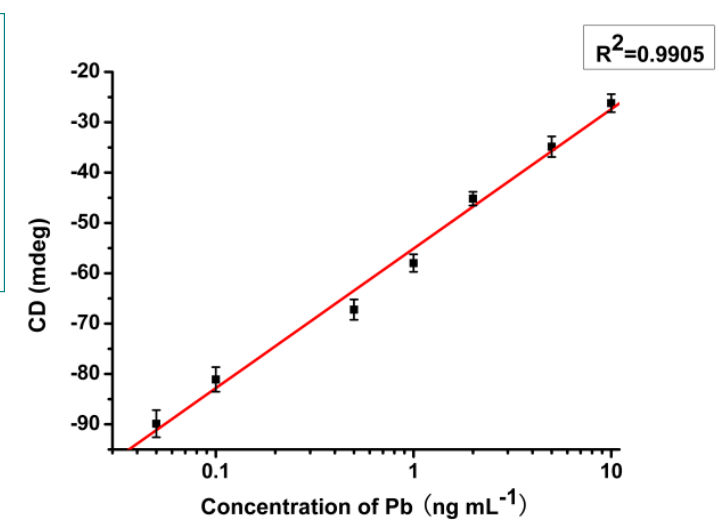

(b)

The specificity and selectively of this method was confirmed by $\mathrm{Mn}^{2+}, \mathrm{Zn}^{2+}, \mathrm{Mg}^{2+}, \mathrm{Fe}^{2+}, \mathrm{Ca}^{2+}, \mathrm{Hg}^{2+}$ and $\mathrm{Cu}^{2+}$ at a concentration of $5 \mathrm{ng} \cdot \mathrm{mL}^{-1}$. There were little differences between $\mathrm{CD}$ signals from other ions and blank control samples while obvious changes in the $\mathrm{CD}$ signal were found in $\mathrm{Pb}^{2+}$ detection (Figure S5). The blank tap water samples spiked at various levels $(0.05,0.1,0.2,0.5,1,2,5$ and $10 \mathrm{ng} \cdot \mathrm{mL}^{-1}$ ) were detected using this sensor. The recovery ratios were found ranging from $94 \%$ to $100 \%$ (Table 1). These results indicated that the DNAzyme based sensor was highly specific in the quantitative detection of $\mathrm{Pb}^{2+}$.

Table 1. Determination of $\mathrm{Pb}^{2+}$ in spiked tap water

\begin{tabular}{ccc}
\hline Spiked level $\left(\mathbf{n g} \cdot \mathbf{m L}^{-\mathbf{1}}\right)$ & Detected level Mean $^{\mathbf{a}} \mathbf{\Phi S D}^{\mathbf{b}}\left(\mathbf{n g} \cdot \mathbf{m L}^{\mathbf{- 1}}\right)$ & Recovery $(\boldsymbol{\%})$ \\
\hline 5 & $4.81 \pm 0.44$ & 96 \\
2 & $1.97 \pm 0.15$ & 98 \\
1 & $0.94 \pm 0.04$ & 94 \\
0.5 & $0.48 \pm 0.05$ & 95 \\
0.2 & $0.19 \pm 0.04$ & 97 \\
0.1 & $0.10 \pm 0.01$ & 100 \\
0.05 & $0.05 \pm 0.01$ & 100 \\
\hline
\end{tabular}

${ }^{\mathrm{a}}$ The mean of five repeats; ${ }^{\mathrm{b}} \mathrm{SD}=$ standard deviation. 


\section{Materials and Methods}

\subsection{Materials and Instruments}

$\mathrm{AgNO}_{3}, \mathrm{NaBH}_{4}$, polyvinyl pyrrolidone (PVP) and trisodium citrate were all purchased from Sigma-Aldrich (Shanghai, China). Tris-acetate buffer (100 mM) was obtained from Shengon Biotechnology Co. Ltd. (Shanghai, China). Other chemicals were of analytical grade and purchased from J\&K Scientific Ltd (Beijing, China). Deionized water was used throughout the experiments and was purified to 18.2 MW (Millipore, Billerica, MA, USA). All the DNA sequences were synthesized by Shengon Biotechnology Co. Ltd. (Shanghai, China) and purified by HPLC. Their detailed sequences were as follows:

\section{S1: 5'-TCACAGATGAGT-SH-3';}

S2: 5'-SH-CACGAGTTGACA-3';

17E: 5'-CATCTCTTCTCCGAGCCGGTCGAAATAGTGAGT-3';

Sub: 5'-ACTCATCTGTGAACTCACTAT(rA)GGAAGAGATGTGTCAACTCGTG-3'.

The ultraviolet-visible spectra were measured using an ultraviolet-visible spectrometer (UV, 200-1000 nm) in a quartz cell. The CD spectra were performed on a Bio-Logic MOS-450 CD spectrometer (Grenoble, France). TEM micrographs were collected on a JEOL-2010 microscope (Tokyo, Japan) operated at $120 \mathrm{kV}$. Dynamic light scattering data were obtained using a Malvern Zetasizer ZS instrument (Malvern, UK) with a $632.8 \mathrm{~nm}$ laser source and a backscattering detector at $173^{\circ}$.

\subsection{Synthesis of Silver NPS}

AgNPs scaled with $10 \pm 3 \mathrm{~nm}$ and $20 \pm 3 \mathrm{~nm}$ were synthesized according to the method described in the literature with minor modifications [38]. Briefly, $0.6 \mathrm{~mL}$ of $0.1 \mathrm{M} \mathrm{NaBH}_{4}$ was dissolved in $20 \mathrm{~mL}$ ice-cold distilled water, and then $5 \mathrm{~mL}$ of a $1 \%$ PVP solution as a protecting agent was added. The mixture was continuously stirred in an ice-water bath. Then $5 \mathrm{~mL}$ of $1 \% \mathrm{PVP}$ and $5 \mathrm{~mL}$ of $10 \mathrm{mM}$ $\mathrm{AgNO}_{3}$ were simultaneously added to the mixture by two constant flow pumps at arate of $30 \mathrm{~mL} / \mathrm{h}$. The solution was kept at $80{ }^{\circ} \mathrm{C}$ for $3 \mathrm{~h}$ to remove excessive $\mathrm{NaBH}_{4}$ and then stored at $4{ }^{\circ} \mathrm{C}$ until use. Finally, AgNPs with a diameter of $10 \mathrm{~nm}$ were obtained. For the preparation of AgNPs with a diameter of $20 \mathrm{~nm}$, similar procedures were used, except $600 \mu \mathrm{L}$ of a $1 \%$ trisodium citrate solution was added in the first step.

\subsection{AgNPs Functionalized with DNA}

The AgNPs (10 nm and $20 \mathrm{~nm}$ ) were condensed tenfold using centrifugation at 10,000 r/min (for small AgNPs) and $8000 \mathrm{r} / \mathrm{min}$ (for larger AgNPs), respectively. The AgNPs were re-suspended in $10 \mathrm{mM}$ Tris- $\mathrm{HCl}$ buffer (containing $50 \mathrm{mM} \mathrm{NaCl}$ ) and the final concentrations of $10 \mathrm{~nm}$ and $20 \mathrm{~nm}$ AgNPs were $50 \mathrm{nM}$ and $20 \mathrm{nM}$, respectively. Then, $1 \mu \mathrm{L}$ of $20 \mu \mathrm{M} \mathrm{S} 1$ was added to $100 \mu \mathrm{L}$ of $20 \mathrm{~nm}$ AgNPs while $1 \mu \mathrm{L}$ of $50 \mu \mathrm{M}$ S2 was incubated with $100 \mu \mathrm{L}$ of $10 \mathrm{~nm}$ AgNPs. The coupling process required $12 \mathrm{~h}$ and the coupling ratio was 10:1 (DNA-AgNP). The successfully functionalized AgNPs were then centrifuged three times to remove the unreacted DNA and resuspended in $50 \mu \mathrm{L}$ of $25 \mathrm{mM}$ Tris-acetate ( $\mathrm{pH} 8.2$, containing $100 \mathrm{mM} \mathrm{NaCl}$ ). 


\subsection{Construction of the DNAzyme-Based Sensor}

For the construction of the DNAzyme based sensor, $70 \mu \mathrm{L}$ of $20 \mathrm{~nm}$ AgNPs-S1, $30 \mu \mathrm{L}$ of $10 \mathrm{~nm}$ AgNPs-S2, $1 \mu \mathrm{L}$ of $100 \mu \mathrm{M}$ Sub and $2 \mu \mathrm{L}$ of $100 \mu \mathrm{M}$ 17E were mixed together, and then the sample was heated to $70{ }^{\circ} \mathrm{C}$ and allowed to cool slowly to room temperature to promote AgNP dimers assembly. Eight hours later, the AgNP assembly was centrifuged three times to obtain the purified dimers, which were used as sensors for $\mathrm{Pb}^{2+}$ detection.

To test the linear response corresponding to the $\mathrm{Pb}^{2+}$ amount, $1 \mu \mathrm{L}$ of $\mathrm{Pb}^{2+}$ in different concentrations (final concentrations ranging from $0.05 \mathrm{ng} \cdot \mathrm{mL}^{-1}$ to $10 \mathrm{ng} \cdot \mathrm{mL}^{-1}$ ) were tested using the system. The reaction system was then incubated in a water bath at $50{ }^{\circ} \mathrm{C}$ for 2 min and gradually cooled to room temperature over $2 \mathrm{~h}$ in the water bath. The products were analyzed by a CD spectra reader.

\subsection{Specificity Tests}

To evaluate the selectivity of this sensor for $\mathrm{Pb}^{2+}$ detection, various other divalent metal ions $\left(\mathrm{Mn}^{2+}\right.$, $\mathrm{Zn}^{2+}, \mathrm{Mg}^{2+}, \mathrm{Fe}^{2+}, \mathrm{Ca}^{2+}, \mathrm{Hg}^{2+}, \mathrm{Cu}^{2+}$ ) were tested at a concentration of $5 \mathrm{ng} \cdot \mathrm{mL}^{-1}$. The procedures were the same as the analysis process for $\mathrm{Pb}^{2+}$ outlined above. All $\mathrm{CD}$ intensity results were compared with the system control and the $\mathrm{Pb}^{2+}$ detection system.

\subsection{Recovery in Tap Water Samples}

$\mathrm{Pb}^{2+}$ was added to negative tap water samples at the following concentrations $0.05,0.1,0.2,0.5,1$, 2 and $5 \mathrm{ng} \cdot \mathrm{mL}^{-1}$. The recovery ratio was then detected by the DNAzyme-based sensor and was calculated based on the CD signals.

\section{Conclusions}

With the aid of DNAzyme, the degree of AgNP assembly was applied for quantification of $\mathrm{Pb}^{2+}$ in water samples. This novel approach takes advantage of the chiral properties of asymmetric AgNP dimers and the unique recognition and catalysis from specific 8-17E DNAzyme. With an increase in $\mathrm{Pb}^{2+}$ concentration, the cleavage degree of DNAzyme and the disassembly of the AgNP dimer correspondingly increased, which resulted in the obvious decrease of the intensity of the CD signal. Under optimized conditions, a LOD of $0.02 \mathrm{ng} \cdot \mathrm{mL}^{-1}$ was obtained in the linear range of $0.05-10 \mathrm{ng} \cdot \mathrm{mL}^{-1}$. An excellent specificity to lead analysis was observed in cross-reaction tests. The proposed measure for lead is highly sensitive, simple and specific for lead analysis, which indicates potential application in the future.

\section{Acknowledgments}

This work is financially supported by the National Natural Science Foundation of China (21071066, 91027038, 21101079, 21175034, 21371081, 21301073), the Key Programs from MOST (2012BAC01B07, 2012AA06A303, 2012BAD29B04, 2012 BAK11B01, 2011BAK10B07, 2011BAK10B01， 2010AA06Z302， 2010DFB3047， 2013ZX08012-001， 2012BAK17B10, 
2012BAK08B01, 2012YQ090194, 2012BAD29B05, 2013AA065501), and grants from Jiangsu Province, MOF and MOE (NCET-12-0879, BE2011626, BE2013613, BE2013611, 201310128, 201210127, 201210036, 201310135, 311002, JUSRP51308A).

\section{Conflicts of Interest}

The authors declare no conflict of interest.

\section{References}

1. Godwin, H.A. The biological chemistry of lead. Curr. Opin. Chem. Biol. 2001, 5, 223-227.

2. Marsden, P.A. Increased body lead burden-cause or consequence of chronic renal insufficiency? N. Engl. J. Med. 2003, 348, 345-346.

3. Magyar, J.S.; Weng, T.C.; Stern, C.M.; Dye, D.F.; Rous, B.W.; Payne, J.C.; Bridgewater, B.M.; Mijovilovich, A.; Parkin, G.; Zaleski, J.M.; Penner-Hahn, J.E.; Godwin, H.A. Reexamination of lead (II) coordination preferences in sulfur-rich sites, implications for a critical mechanism of lead poisoning. J. Am. Chem. Soc. 2005, 127, 9495-9505.

4. Verstraeten, S.V.; Aimo, L.; Oteiza, P.I. Aluminium and lead, molecular mechanisms of brain toxicity. Arch. Toxicol. 2008, 82, 789-802.

5. Grinshtein, I.L.; Vilpan, Y.A.; Vasilieva, L.A.; Kopeikin, V.A. Direct atomic absorption determination of cadmium and lead in strongly interfering matrices by double vaporization with a two-step electrothermal atomizer. Spectrochim. Acta Part B Atomic Spectrosc. 2001, 56, 261-274.

6. Aydin, F.A.; Soylak, M. Separation, preconcentration and inductively coupled plasma-mass spectrometric (ICP-MS) determination of thorium (IV), titanium (IV), iron (III), lead (II) and chromium (III) on 2-nitroso-1-naphthol impregnated MCI GEL CHP20P resin. J. Hazard. Mater. 2010, 173, 669-674.

7. Robertson, D.L.; Joyce, G.F. Selection in vitro of an RNA enzyme that specifically cleaves single-stranded DNA. Nature 1990, 344, 467-468.

8. Breaker, R.R. DNA enzymes. Nat. Biotechnol. 1997, 15, 427-431.

9. Joyce, G.F. Directed evolution of nucleic acid enzymes. Annu. Rev. Biochem. 2004, 73, 791-836.

10. Keiper, S.; Vyle, J.S. Reversible photocontrol of deoxyribozyme-catalyzed RNA cleavage under multiple-turnover conditions. Angew. Chem. 2006, 118, 3384-3387.

11. Willner, I.; Shlyahovsky, B.; Zayats, M.; Willner, B. DNAzymes for sensing, nanobiotechnology and logic gate applications. Chem. Soc. Rev. 2008, 37, 1153-1165.

12. Lu, Y.; Liu, J. Functional DNA nanotechnology, emerging applications of DNAzymes and aptamers. Curr. Opin. Biotechnol. 2006, 17, 580-588.

13. Lu, Y.; Liu, J. Smart nanomaterials inspired by biology, dynamic assembly of error-free nanomaterials in response to multiple chemical and biological stimuli. Acc. Chem. Res. 2007, 40, $315-323$.

14. Liu, J.; Cao, Z.; Lu Y. Functional nucleic acid sensors. Chem. Rev. 2009, 109, 1948-1998.

15. Wang, Z.; Lu, Y. Functional DNA directed assembly of nanomaterials for biosensing. J. Mater. Chem. 2009, 19, 1788-1798. 
16. Xiang, Y.; Wang, Z.; Xing, H.; Lu, Y. Expanding DNAzyme functionality through enzyme cascades with applications in single nucleotide repair and tunable DNA-directed assembly of nanomaterials. Chem. Sci. 2013, 4, 398-404.

17. Liu, J.; Lu, Y. A colorimetric lead biosensor using DNAzyme-directed assembly of gold nanoparticles. J. Am. Chem. Soc. 2003, 125, 6642-6643.

18. Liu, J.; Lu, Y. Accelerated color change of gold nanoparticles assembled by DNAzymes for simple and fast colorimetric $\mathrm{Pb}^{2+}$ detection. J. Am. Chem. Soc. 2004, 126, 12298-12305.

19. Xiao, Y.; Rowe, A.A.; Plaxco, K.W. Electrochemical detection of parts-per-billion lead via an electrode-bound DNAzyme assembly. J. Am. Chem. Soc. 2007, 129, 262-263.

20. Chen, Y.-Y.; Chang, H.-T.; Shiang, Y.C.; Hung, Y.L.; Chiang, C.K.; Huang, C.C. Colorimetric assay for lead ions based on the leaching of gold nanoparticles. Anal. Chem. 2009, 81, 9433-9439.

21. Zhu, X.; Lin, Z.; Chen, L.; Qiu, B.; Chen, G. A sensitive and specific electrochemiluminescent sensor for lead based on DNAzyme. Chem. Commun. 2009, 40, 6050-6052.

22. Mazumdar, D.; Liu, J.; Lu, G.; Zhou, J.; Lu, Y. Easy-to-use dipstick tests for detection of lead in paints using non-cross-linked gold nanoparticle-DNAzyme conjugates. Chem. Commun. 2010, 46, $1416-1418$.

23. Miao, X.; Ling, L.; Shuai, X. Ultrasensitive detection of lead (II) with DNAzyme and gold nanoparticles probes by using a dynamic light scattering technique. Chem. Commun. 2011, 47, 4192-4194.

24. Zhang, Z.; Balogh, D.; Wang, F.; Willner, I. Smart mesoporous $\mathrm{SiO}_{2}$ nanoparticles for the DNAzyme-induced multiplexed release of substrates. J. Am. Chem. Soc. 2013, 135, 1934-1940.

25. Xia, Y.; Zhou, Y.; Tang, Z. Chiral inorganic nanoparticles, origin, optical properties and bioapplications. Nanoscale 2011, 3, 1374-1382.

26. Zhu, Z.; Liu, W.; Li, Z.; Han, B.; Zhou, Y.; Gao, Y.; Tang, Z. Manipulation of collective optical activity in one-dimensional plasmonic assembly. ACS Nano 2012, 6, 2326-2332.

27. Wang, Y.; Xu, J.; Wang, Y.; Chen, H. Emerging chirality in nanoscience. Chem. Soc. Rev. 2013, 42, 2930-2962.

28. Mastroianni, A.J.; Claridge, S.A.; Alivisatos, A.P. Pyramidal and chiral groupings of gold nanocrystals assembled using DNA scaffolds. J. Am. Chem. Soc. 2009, 131, 8455-8459.

29. Kuzyk, A.; Schreiber, R.; Fan, Z.; Pardatscher, G.; Roller, E.M.; Högele, A.; Simmel, F.C.; Govorov, A.O.; Liedl, T. DNA-based self-assembly of chiral plasmonic nanostructures with tailored optical response. Nature 2012, 483, 311-314.

30. Li, Z.; Zhu, Z.; Liu, W.; Zhou, Y.; Han, B.; Gao, Y.; Tang, Z. Reversible plasmonic circular dichroism of Au nanorod and DNA assemblies. J. Am. Chem. Soc. 2012, 134, 3322-3325.

31. Yan, W.; Xu, L.; Xu, C.; Ma, W.; Kuang, H.; Wang, L.; Kotov, N.A. Self-assembly of chiral nanoparticle pyramids with strong R/S optical activity. J. Am. Chem. Soc. 2012, 134, 15114-15121.

32. Zhao, Y.; Xu, L.; Kuang, H.; Wang, L.B.; Xu, C.L. Asymmetric and symmetric PCR of gold nanoparticles, a pathway to scaled-up self-assembly with tunable chirality. J. Mater. Chem. 2012, $22,5574-5580$. 
33. Zhao, Y.; Xu, L.; Liz-Marzán, L.M.; Kuang, H.; Ma, W.; Asenjo-García, A.; Garcia de Abajo, J.; Kotov, N.A.; Wang, L.; Xu, C. Alternating plasmonic nanoparticle heterochains made by polymerase chain reaction and their optical properties. J. Phys. Chem. Lett. 2013, 4, 641-647.

34. Xu, Z.; Xu, L.; Zhu, Y.; Ma, W.; Kuang, H.; Wang, L.; Xu, C. Chirality based sensor for bisphenol A detection. Chem. Commun. 2012, 48, 5760-5762.

35. Zhu, Y.; Xu, L.; Ma, W.; Xu, Z.; Kuang, H.; Wang, L.B.; Xu, C.L. A one-step homogeneous plasmonic circular dichroism detection of aqueous mercury ions using nucleic acid functionalized gold nanorods. Chem. Commun. 2012, 48, 11889-11891.

36. Kim, H.; Ren, W.; Kim, J.; Yoon, J. Fluorescent and colorimetric sensors for detection of lead, cadmium, and mercury ions. Chem. Soc. Rev. 2012, 41,3210-3244.

37. Kuang, H.; Xing, C.R.; Hao, C.L.; Liu, L.Q.; Wang, L.B.; Xu, C.L. Rapid and highly sensitive detection of lead ions in drinking water based on a strip immunosensor. Sensors 2013, 13, 4214-4224.

38. Sun, Y.; Xia, Y. Triangular nanoplates of silver, synthesis, characterization, and use as sacrificial templates for generating triangular nanorings of gold. Adv. Mater. 2003, 15, 695-699.

(C) 2013 by the authors; licensee MDPI, Basel, Switzerland. This article is an open access article distributed under the terms and conditions of the Creative Commons Attribution license (http://creativecommons.org/licenses/by/3.0/). 